\title{
On the electrical and capillary properties of mercury in contact with different aqueous solutions
}

\section{Lippmann}

To cite this article: M. Lippmann (1877) On the electrical and capillary properties of mercury in contact with different aqueous solutions, Philosophical Magazine Series 5, 4:24, 238-239, DOI: $10.1080 / 14786447708639330$

To link to this article: http://dx.doi.org/10.1080/14786447708639330

曲 Published online: 13 May 2009.

Submit your article to this journal $[\pi$

Џll Article views: 2

Q View related articles $\sqsubset$ 


\section{[ 238$]$ \\ XXXI. Intelligence and Miscellaneous Articles.}

ON THE ELECTRICAL AND CAPILLARY PROPERTIES OF MERCURY

IN CONTACT WITH DIFFEREN'T AQUEOUS SOLUTIONS. BY M. LIPPMANN.

WHEN mercury is in contact with pure or acidulated water, one

has only to add to the water a small quantity of certain substances in order to notably change two of the physical properties of the contact surface-the capillary constant or superficial tension, on the one hand, and, on the other, the electromotive force (that is to say, the difference of the electrical potentials) of the water and the mercury. The experiments which I have made on this question, in the laboratory of M. Jamin, and which I have the honour of submitting to the Academy, have conducted me to this very simple relation :-For each value of the electromotive force the capillary constant has a determinate value, and one only, independent of the chemical composition of the liquid. In other terms, if for two different combinations the electromotive force is the same, the capillary constant is litewise the same.

To verify this law, I at first employed the following very simple apparatus :-Two equal capillary tubes, $T, T^{\prime}$, are placed vertically side by side, and communicate by their lower part with one and the same reservoir of mercury ; their upper extremities are furnished with two funnels, $\mathrm{E}, \mathrm{E}^{\prime}$, to receive the liquids for experiment. If the same liquid has been put into both $\mathrm{E}$ and $\mathrm{E}^{\prime}$ (e.g. water to which has been added one sixth of its volume of sulphuric acid *), the capillary depression of the mercury is the same in both tubes, since all is symmetrical on both sides. In one of the tubes a little chlorhydric acid or a trace of bichromate of potash is added (the former of these substances augments, the latter diminishes the depression of the mercury); the meniscuses cease to be of the same height in both tubes. The reservoirs $\mathrm{E}$ and $\mathrm{E}^{\prime}$ are then put into electric communication with one another by means of a fine tube filled with acidulated water. The mercury menisenses are immediately seen to begin to move towards the same horizontal plane, where they come to rest. The tube of communication has been traversed by an electric current of short duration, the effect of which has been to equalize the electromotive forces of the two meniscuses ; the equality of these forces has brought with it that of the capillary constants, which demonstrates the law enunciated. When the electric communication is suppressed the inequality of the electrical differences is reproduced, and at the same time the difference of level.

Another verification, of great nicety, has been obtained by means of a more perfect apparatus. A vertical tube, open at both ends, is tapered to a fine point at its lower extremity. It contains a column of mercury of about 40 centims. height, which is supported by the capillary pressure of the minute meniscus which is formed in the slender point. This point dips into a glass vessel $V$ con-

* This acidulated has over pure water the advantage of well wetting the glass, which eliminates the variations of the angle of junction between the two. 
taining dilute sulphuric acid, with which can be mixed substances suitable for causing the capillary constant of the meniscus to varysuch as chlorhydric acid, chromic acid, \&c. The electrical difference of the meniscus can be maintained constant. For that purpose the mercury and the liquid under experiment are put in communication respectively with some mercury and acidulated water contained in a large vessel $V^{\prime}$. It can then be ascertained that the changes in composition of the liquid $V$ do not cause the position of the meniscus to vary; this can be verified by means of a microscope with a reticule. If the electrical communications described above be suppressed, the meniscus becomes, on the contrary, very sensitive to the changes of chemical composition of the liquid.

It is necessary to employ for these experiments substances which, in small quantities, act powerfully on the capillary constant; two aqueous solutions put into contact do not take sensibly the same electrical potential, unless they have nearly the same chemical composition. Between two very different liquids, such as chlorhydric and sulphuric aeids, taken each pure and diluted, an electromotive force of contact is produced, which would complicate the experiment. As bodies active in small quantities we may mention (1) the hydro-acids and hyposulphite of soda, and (2) bichromate and permanganate of potash in the presence of acids. Chlorine, sulphurous acid, and carbonic acid, on the contrary, have but little action. Bromine and iodine act in the same direction as the hydrogen acids, and in the opposite direction to the oxidizing bodies, such as chromic acid.-Comptes Rendus de l'Académie des Sciences, July 16, 1877, tome lxxxv. pp. 142-144.

NOTE ON THE EFFECT OF CHROMATIC ABERRATION IN DISTANT VISION. BY B. THOMPSON LOWNE, F.R.C.S., ARRIS AND GALE LECTURER ON ANATOMY AND PHYSIOLOGY IN THE ROYAI COLLEGE OF SURGEONS, LECTURER ON PHYSIOLOGY IN THE MIDDLESEX HOSPITAL MEDICAL SCHOOL, OPHTHALMIC SURGEON TO THE GREAT NORTHERN HOSPITAL.

Mr. S. P. Thompson, in a communication on this subject published in the July Part of the 'Philosophical Magazine' speaks of chromatic aberration as if it were an advantage in distant vision. I fail to understand, however, how this can be the case. There can be no doubt that distant objects are seen with a predominance of the more refrangible blue and violet rays; an eye, therefore, which is emmetropic for such rays is hypermetropic for the less-refrangible red rays. Taking the dispersive power of the eye as equal to that of water, this hypermetropia amounts to two dioptrics. Such an eye would therefore have the red objects of the foreground more out of focus than if it were achromatic. An eye which is emmetropic for red would on the other hand have blue objects accurately focused, without any accommodation, if they were situated at a distance of half a metre from the eye. No doubt, if red and blue are situated on the same plane at the same distance from the eye, as the red requires the greatest effort of accommodation it will appear 